\title{
Characterization, Biological Activity and DNA Studies of Atomexetine and Ortho hydroxy benzaldehyde Imine Metal Complexes
}

\author{
G. S. SANJANEYA VASAVI ${ }^{1}$ and J. SREERAMULU ${ }^{2}$ \\ 'Department of Chemistry, RGM College of Engineering \& Technology, Nandyal, Andhra Pradesh, India. \\ ${ }^{2}$ Department of Chemistry, S.K University, Anantapuramu, Andhra Pradesh, India. \\ Corresponding author E-mail: vasavi.sunny@gmail.com \\ http://dx.doi.org/10.13005/ojc/360331
}

(Received: May 26, 2020; Accepted: June 22, 2020)

\section{ABSTRACT}

\begin{abstract}
The rapid increasing applications and anti-bacterial and anti hyperactive properties of different drug the author have synthesized Imine complexes of Atomexetine with O-hydroxy benzaldehyde. These were depicted with various techniques via Elemental Analysis, UV, FT-IR, NMR, ESR, VSM, Conductivity and TG-DTA. These ligands and metal complexes were also screened for biological activity and DNA Studies.
\end{abstract}

Keywords: Atomexetine, Copper chloride, Ruthenium chloride and Biological activity.

\section{INTRODUCTION}

Imines are the condensed products of Carbonyl compounds and Amines ${ }^{1}$. These are also known as Schiff Bases. The Scientist Hugo Schiff was introduced in $1864^{2}$. Imines show a unique property in the participation of covalent bond with transition metal ions, since the easy formation of ligands act as intermediates for the formation of complexes with transition metal ions. Imine complexes perform biological activities like anti inflammatory, anti fungal, anti bacterial, anti viral, anti diabetic, anti cancer and in pharmaceuticals etc ${ }^{3-9}$. Biological activity of the Ligands were recorded by the presence of $>\mathrm{C}=\mathrm{N}$ moiety of the Schiff bases. These are also having uncountable appliances in technical fields like automobiles, electro plating, printing technology, textile and detergents ${ }^{10-11}$.

The author has reported characterization, biological activity and DNA studies of the ligands and their metal complexes. The synthesis of Imine metal complexes has been carried out by conventional method and characterization with various techniques like FT-IR, $\mathrm{H}^{1}$-NMR, ESR, UV-Vis and Conductometry. Thermal stability of the complexes was identified by TG-DTA with various temperatures. Biological activity of Imines and their $\mathrm{Cu}$ and Ru complexes was performed in In vitro conditions and DNA binding mode with UV-Vis Spectroscopic technique.

This is an Open Access article licensed under a Creative Commons license: Attribution 4.0 International (CC- BY). Published by Oriental Scientific Publishing Company @ 2018

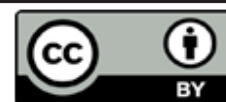




\section{MATERIALS AND METHODS}

Atomexetine (AT), O-hydroxy benzaldehyde (OHB), methanol, DMF, chlorides of Copper and ruthenium.

\section{Instrumentation}

IR Spectral data with $\mathrm{KBr}$ Pellets, $\mathrm{H}^{1}-\mathrm{NMR}$ Spectral data with BRUKER 400MHZ SUPERCON Spectrometer, ESR Spectral data with Bruker ESP 300E spectrometer, UV-Vis Spectral data with Schimadzu UV-1800 model Spectrometer, XRD on Panalytical X'pert3 difractometer, conductivity measurements with digital conductivity meter DCM-900, VSM with EG and G-155 magnetometer were recorded.

\section{Synthesis of OHB-AT Ligand}

The equal concentration of $\mathrm{AT}$ and $\mathrm{OHB}$ was dissolved separately, this mixture was heated for $2 \mathrm{~h}$ by adding few drops of concentrated $\mathrm{HCL}$, pink colored solution was obtained and this was cooled to room temperature. Then pink color precipitate was obtained. These crystals were washed with methanol and dried in micro wave. The percentage yield of ligand was 80 .

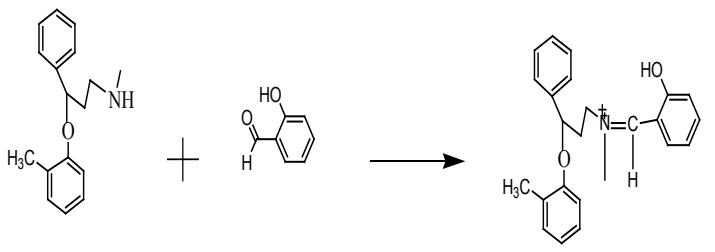

Scheme 1. Synthesis of OHB-AT Ligand

Synthesis of OHBAT-Cu(II) \& Ru(III) metal complexes

The complexes were prepared by mixing $1: 2$ ratio of an aqueous solution of metal ions with the methanolic solution of Imine separately and stirred with magnetic stirrer for proper mixing of contents. Then the contents in the flask were reflexed for six hours and kept in ice bath for cooling, bluish green color sharp needle like crystals were obtained. These were washed and recrystallized with methanol. The yield of copper and ruthenium complexes was $75 \%$ and $78 \%$.

\section{RESULTS AND DISCUSSIONS}

The main purpose of the present work is to study the characterization of metal complexes with various techniques, Biological activity in In vitro conditions with different micro-organisms and DNA studies on UV-Vis Spectrophotometer.

\section{IR spectral data}

The nature of Imine metal complexes were identified by obtaining strong band at $1627 \mathrm{~cm}^{-1}$ indicated the development of Imine group, which on complexing with the metals viz. $\mathrm{Cu}$ (II) and Ru (III) the bands appeared at $1605 \mathrm{~cm}^{-1}$ and $1622 \mathrm{~cm}^{-1}$ indicated the coordination between Imine group of nitrogen with electron deficient metal ions because of decreased electron density on Nitrogen atom ${ }^{12,13}$. The another strong bands at $420 \mathrm{~cm}^{-1}$ and $429 \mathrm{~cm}^{-1}$ for copper and ruthenium expressed coordination between metal and ligand ${ }^{14,15}$. IR data of the ligand and complexes were represented in the Table 1.

Table 1: IR Spectral data of the ligand and its complexes

\begin{tabular}{lccccc}
\hline Compound $v$ OH Water $v$ OH Phenolic & $v \mathrm{C}=\mathrm{N}$ & $v \mathrm{M}-\mathrm{O}$ & $v \mathrm{M}-\mathrm{N}$ \\
\hline OHBAT & - & 3363 & 1627 & - & - \\
OHBAT-Cu & 3304 & - & 1605 & 620 & 420 \\
OHBAT-Ru & 3413 & - & 1622 & 649 & 429 \\
\hline
\end{tabular}

\section{NMR spectral data}

A singlet at $5.6 \mathrm{ppm}$ revealed aromatic- $\mathrm{OH}$ protons of $\mathrm{OHB}$, this was absent in complex given the coordination between oxygen moiety of $\mathrm{OHB}$ and metal ions of $\mathrm{Cu}$ (II) and Ru (III). A singl et at., $6.26 \mathrm{ppm}$ specified the presence of Imine group of ligand $^{16}$, this was shifted to $7.6 \mathrm{ppm}$ and $7.26 \mathrm{ppm}$ by the coordination of ligand with metal ions. Another singlet at $4.1 \mathrm{ppm}$ and $4.65 \mathrm{ppm}$ appeared only by the coordination of water molecules with metal ions. NMR data of the ligand and complexes were represented in the Table 2.

Table 2: NMR spectral data of OHBAT and its metal complexes

\begin{tabular}{ccccccc}
\hline S.No Compound & $\mathrm{H}-\mathrm{C}=\mathrm{N}$ & $\mathrm{Ar}-\mathrm{H}$ & $\mathrm{OH}-$ Phenilic & $\mathrm{OH}-\mathrm{H}_{2} \mathrm{O}$ & $-\mathrm{CH}_{3}$ \\
\hline 1 & OHBAT & 6.26 & $6.7-7.3$ & 5.6 & - & 3.4 \\
2 & OHBAT-Cu & 7.2 & $7.4-7.9$ & - & 4.1 & 3.7 \\
3 & OHBAT-Ru & 7.26 & $7.3-7.7$ & - & 4.65 & 3.3 \\
\hline
\end{tabular}

\section{ESR spectral data}

The value of $G$ is $>4$ shows mononuclear nature of complex. This value can be calculated as, $\mathrm{G}=\left[\mathrm{g}^{\prime \prime}\right.$ $\left.2.0023 / g^{\perp}-2.0023\right]$.

$\alpha^{2}$ value of Copper and Ruthenium complexes(0.4518 and 0.4794$)$ specified the covalent nature of complexes. The values of $\mathrm{g}^{\prime \prime}$ 
$>g_{\text {ave }}>g^{\perp}$ values were greater than 2.0023 said that unpaired electrons of $\mathrm{d}_{x-y}{ }^{2}{ }^{2}$ and $\mathrm{d}_{\mathrm{z}}{ }^{2}$ orbital is delocalized for $\mathrm{Cu}$ and $\mathrm{Ru}$ ions respectively ${ }^{17}$. ESR spectral data of the complexes were represented Table in 3.

Table 3: ESR Spectral data of OHBAT-Cu and OHBAT-Ru

\begin{tabular}{ccc}
\hline Parameters & OHBAT-Cu & OHBAT-Ru \\
\hline $\mathrm{g}^{\|}$ & 2.5864 & 2.6885 \\
$\mathrm{~g}^{\perp}$ & 2.2038 & 2.3698 \\
$\mathrm{~g}_{\text {ave }}$ & 2.3313 & 2.4968 \\
$\mathrm{G}$ & 4.327 & 4.5138 \\
$\mathrm{~A}^{\| *}$ & 0.00869 & 0.00981 \\
$\mathrm{~A}^{\perp *}$ & 0.0097 & 0.0168 \\
$\mathrm{~A}_{\text {ave }}$ & 0.0099 & 0.0126 \\
$\mathrm{~K}^{\|}$ & 0.0762 & 0.0865 \\
$\mathrm{~K}^{\perp}$ & 0.0848 & 0.0896 \\
$\mathrm{P}^{*}$ & 0.0336 & 0.0418 \\
$\alpha^{2}$ & 0.2798 & 0.4198 \\
\hline
\end{tabular}

\section{UV-Vis spectral data}

The transition of ligand was $277 \mathrm{~nm}$, which on complexation with $\mathrm{Cu}$ (II) and $\mathrm{Ru}$ (III) metal complexes change in transitions at $289 \mathrm{~nm}$ and $306 \mathrm{~nm}$ signified the charge transfer transition from $L \rightarrow M^{18}$. UV-Vis Spectral data was represented in the Table 4.

Table 4: UV-Vis Spectral of OHBAT and ITS Cu (II) and Ru (III) Metal complexes

\begin{tabular}{lll}
\hline S.No & compound & $\lambda_{\max }$ \\
\hline 1 & OHBAT & 277 \\
2 & OHBAT-Cu & 289 \\
3 & OHBAT-Ru & 306 \\
\hline
\end{tabular}

XRD of OHBAT-Cu and OHBAT-Ru metal complexes

The diffracto grams, calculated miller indices

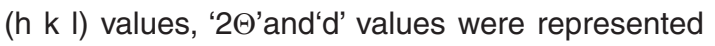
in the Table 5 suggested a good agreement between'2 $\Theta$ ' and'd' values. $2 \Theta$ values recommended poor crystallinity of the complexes ${ }^{19}$.

The miller indices values are calculated as, $\mathrm{N} \lambda=2 \mathrm{~d} \sin \Theta$

One of the value of

$$
\begin{aligned}
& 2 \Theta=5.2805 \\
& \Theta=2.64025 \\
& \operatorname{Sin} \Theta=0.046064 \\
& \text { h k I }=111
\end{aligned}
$$

XRD values of the complexes were represented in the Tables 5-6.
Table 5: XRD studies of OHBAT-Cu metal complex

\begin{tabular}{cccccccc}
\hline S.No & d exp & d Cal. & $2 \Theta$ exp & $2 \Theta$ Cal. & h $k ~ l$ \\
\hline 1 & 0.0354 & 0.0349 & 5.2805 & 5.2801 & 1 & 1 & 1 \\
2 & 0.03917 & 0.03912 & 5.8303 & 5.8299 & 1 & 1 & 1 \\
3 & 0.04428 & 0.04422 & 6.5921 & 6.5915 & 1 & 1 & 1 \\
4 & 0.04925 & 0.04919 & 7.3326 & 7.3321 & 2 & 1 & 1 \\
5 & 0.05915 & 0.05910 & 8.8085 & 8.8081 & 2 & 2 & 1 \\
6 & 0.0623 & 0.0619 & 9.2791 & 9.2785 & 2 & 2 & 1 \\
7 & 0.0965 & 0.0959 & 14.3999 & 14.3994 & 5 & 4 & 4 \\
8 & 0.1039 & 0.1033 & 15.5905 & 15.5901 & 5 & 5 & 2 \\
9 & 0.1088 & 0.1081 & 16.2419 & 16.2414 & 5 & 5 & 3 \\
10 & 0.1255 & 0.1250 & 18.7663 & 18.7659 & 6 & 6 & 3 \\
11 & 0.1311 & 0.1308 & 19.6003 & 19.6000 & 6 & 6 & 4 \\
12 & 0.1466 & 0.1459 & 21.9204 & 21.9199 & 6 & 6 & 6 \\
13 & 0.1800 & 0.1796 & 27.0421 & 27.0415 & 9 & 8 & 4 \\
14 & 0.1891 & 0.1886 & 28.4342 & 28.4339 & 9 & 9 & 4 \\
15 & 0.1948 & 0.1944 & 29.2495 & 29.2489 & 9 & 9 & 5 \\
16 & 0.2165 & 0.2161 & 32.6565 & 32.6559 & 10 & 10 & 6 \\
17 & 0.2308 & 0.2301 & 34.8814 & 34.8809 & 11 & 10 & 7 \\
18 & 0.2582 & 0.2579 & 39.1821 & 39.1816 & 12 & 11 & 8 \\
19 & 0.2882 & 0.2876 & 42.9935 & 42.9931 & 12 & 11 & 10 \\
20 & 0.2929 & 0.2924 & 44.7026 & 44.7021 & 12 & 12 & 12 \\
21 & 0.2982 & 0.2976 & 45.5550 & 45.5546 & 13 & 13 & 10 \\
22 & 0.3252 & 0.3249 & 49.9612 & 49.9606 & 14 & 14 & 12 \\
23 & 0.3742 & 0.3737 & 58.1390 & 58.1384 & 16 & 16 & 14 \\
24 & 0.4059 & 0.4055 & 63.5485 & 63.5481 & 17 & 17 & 16 \\
25 & 0.4693 & 0.4688 & 75.0662 & 75.0658 & 20 & 19 & 19 \\
26 & 0.5132 & 0.5129 & 83.560 & 83.555 & 21 & 21 & 20 \\
\hline & & & & & & & \\
\hline
\end{tabular}

Table 6: XRD studies of OHBAT-Ru metal complex

\begin{tabular}{cccccccc}
\hline S.No & d exp & d Cal. & $2 \Theta \exp$ & $2 \Theta$ Cal. & \multicolumn{2}{c}{ h k l } \\
\hline 1 & 0.0407 & 0.0401 & 6.0709 & 6.0701 & 1 & 1 & 1 \\
2 & 0.0490 & 0.0485 & 7.2553 & 7.2549 & 1 & 1 & 1 \\
3 & 0.0563 & 0.0558 & 8.3951 & 8.3945 & 2 & 1 & 1 \\
4 & 0.0634 & 0.0631 & 9.4552 & 9.4546 & 2 & 2 & 1 \\
5 & 0.0855 & 0.0851 & 12.7476 & 12.7470 & 4 & 4 & 2 \\
6 & 0.0934 & 0.0929 & 13.9398 & 13.9392 & 5 & 4 & 1 \\
7 & 0.1246 & 0.1241 & 18.6317 & 18.6312 & 6 & 5 & 4 \\
8 & 0.1306 & 0.1299 & 19.5272 & 19.5266 & 6 & 6 & 4 \\
9 & 0.1328 & 0.1321 & 19.9280 & 19.9274 & 7 & 6 & 1 \\
\hline
\end{tabular}

\section{Analysis of TG-DTA}

By observing modifications at different temperature ranges one can easily explain thermal stability of the complexes. The temp ranges between $110^{\circ} \mathrm{C}-222.10^{\circ} \mathrm{C}$ and $215^{\circ} \mathrm{C}-280^{\circ} \mathrm{C}$ specified the loss of two water molecules at the first level ${ }^{20}$, the second level at $261.03^{\circ} \mathrm{C}$ and $450^{\circ} \mathrm{C}$ specified the formation of stable intermediate peaks as the results of decomposition at the temperature range of $818^{\circ} \mathrm{C}$ and $600^{\circ} \mathrm{C}$. At high temp metallic oxides formation takes by the exothermic process. Thermal data of $\mathrm{Cu}$ (II) and Ru (III) metal complexes were represented in the Table 7. 
Table 7: Thermal Data of OHBAT-Cu \& OHBAT-Ru Metal Complexes

\begin{tabular}{lccccc}
\hline Complex & Molecular weight (grams) & Temperature range in ${ }^{\circ} \mathrm{C}$ & Probable assignment & Mass loss (\%) & Total mass loss (\%) \\
\hline OHBAT-Cu & 894.68 & $110-222.10$ & Loss of two $\mathrm{H}_{2}$ O molecules & 4.5 \\
& & Loss of two ligand molecules & 25.53 \\
& & Formation of CuO & 40.35 \\
OHBAT-Ru & 932.41 & Above 818.34 & & 5.35 & 70.22 \\
& & $215-280$ & Loss of two $\mathrm{H}_{2}$ O molecules & Loss of two ligand molecules & 27.35 \\
& $450-600$ & Formation of CuO & 55.63 \\
\hline
\end{tabular}

\section{Conductometry}

Molar Conductivity value of the complexes at 58 and $60 \mathrm{Ohm}^{-1} \mathrm{~cm}^{2} \mathrm{~mol}^{-1}$ for $\mathrm{Cu}(\mathrm{II})$ and $\mathrm{Ru}(\mathrm{III})$ specified non electrolytic in nature ${ }^{21}$. Molar conductance values of the complexes were represented in the Table 8.

Table 8: conductivity values of OHBAT-Cu (II) and OHBAT-Ru(III) metal complexes

\begin{tabular}{ccc}
\hline S.No & Complex & $\begin{array}{c}\text { Conductance } \\
\mathrm{Ohm}^{-1} \mathrm{~cm}^{2} \mathrm{~mol}^{-1}\end{array}$ \\
\hline 1 & OHBAT-Cu & 58 \\
2 & OHBAT-Ru & 60 \\
\hline
\end{tabular}

\section{VSM analysis}

The magnetic momentum values of OHBAT-Cu and OHBAT-Ru complexes at 4.28 and 5.56 BM specified octahedral geometry ${ }^{22,23}$ of the complexes due to the presence of lone pair of electrons in d-orbital of the metal ions. The magnetic susceptibility values of OHBAT-Cu and OHBAT-Ru complexes were represented in the Table 9.

Table 9: Magnetic momentum values of OHBAT-Cu and OHBAT-Ru complexes

\begin{tabular}{lcc}
\hline S.No & Complex & Magnetic momentum (BM) \\
\hline 1 & OHBAT-Cu & 4.28 \\
2 & OHBAT-Ru & 5.56 \\
\hline
\end{tabular}

\section{Biological studies}

Biological studies of the ligands and complexes were performed in In vitro conditions; represented biological activity of Imines was less than their corresponding metal complexes because of the reduced electron density of metal ions by the transfer of charge, according to Chelating theory ${ }^{24}$. The biological activity values of Imines and their metal complexes were represented in the Table 10.
Table 10: Biological studies of the metal complexes of Copper \& Ruthenium metal ions

\begin{tabular}{lccc}
\hline Compound & E. coli & Klebsiella & Bacillus \\
\hline OHBAT & 9 & 11 & 14 \\
OHBAT-Cu & 10 & 13 & 15 \\
OHBAT-Ru & 11 & 14 & 16 \\
\hline
\end{tabular}

\section{DNA binding mode of the complexes}

DNA binding activity of the complexes was performed with di sodium salt of calf DNA. The spectrum was performed in the absence and presence of CT-DNA. In the presence of CT-DNA the complexes conveyed hypochromic shift because of the presence of chromophores of the ligand. The quantitative comparisons of binding parameters from the following equation

$$
[D N A] /\left(\varepsilon_{\mathrm{a}}-\varepsilon_{\mathrm{f}}\right)=[\mathrm{DNA}] /\left(\varepsilon_{\mathrm{b}}-\varepsilon_{\mathrm{f}}\right)+1 \mathrm{~K}_{\mathrm{b}}\left(\varepsilon_{\mathrm{b}}-\varepsilon_{\mathrm{f}}\right)
$$

The binding constants of the complexes were represented in the Table 11.

Table 11: DNA activity of OHBAT-Cu and OHBAT-Ru metal complexes

\begin{tabular}{ccccccc}
\hline S.No & Complex & $\begin{array}{c}\lambda_{\max } \\
\text { Free }\end{array}$ & $\begin{array}{c}\mathrm{nm} \\
\text { Bound }\end{array}$ & $\Delta \lambda \mathrm{nm}$ & $\mathrm{H} \%$ & $\mathrm{~K}_{\mathrm{b}}\left(\mathrm{M}^{-1}\right)$ \\
\hline 3 & OHBAT-Cu & 305 & 311 & 6 & 6.35 & $3.94 \times 10^{6}$ \\
4 & OHBAT-Ru & 313 & 317 & 6 & 6.29 & $3.28 \times 10^{6}$ \\
\hline
\end{tabular}

\section{CONCLUSION}

In the present article author has reported characterization, biological activity and DNA studies of the metal complexes of $\mathrm{Cu}$ (II) and Ru (III) metal ions. The characterization reports suggested, the complex was mono nuclear with molecular formula of $\left[\mathrm{M}(\mathrm{L})_{2}\right]$. The stoichiometry of the complex was $1: 2$ ratios and proposed geometry of the complexes was octahedral. The complexes were exhibit more biological activity than their corresponding ligands. 


\section{ACNOWLEDGEMENT}

1) I would like to express my deepest appreciation to my Professor J. Sreeramulu garu department of chemistry, SK University, Anantapuramu for his continuous support in my research area.
2) I would like thanks to RGM college of Engineering and technology for encouraging in the area of research.

\section{Conflicts of interest}

The author has no conflicts regarding publication of this paper.

\section{REFERENCES}

1. Sreenatha Sharma, T.; Sreeramulu, J.; Siddaiah, M.; Global trends pharm Sci., 2017, 8, 4528-4536.

2. Schiff, Ann. Chem., 1864, 131, 118-119.

3. Sreevidhya, N.; Arulanantham Xavier, Dr.; IJREAT., 2017, 4, 1-10.

4. Xie, M.; yang, X.D.; Liu, W.; Yan, S.; Meng, Z.; J. Inorg. Biochem., 2010, 104, 851-857.

5. Montalban, A.G.; Alonso, J.; White, A.J.P.; Williams, D.J.; Tetrahedron Lett., 2010, 51, 5543-5545.

6. Feng Jiao,Ti.; Juan Zhou1, JingXin Zhou1, LiHua Gao1, YuanYuan Xing1, and XuHui Li1, Iranian Polymer Journal., 2011, 20(2).

7. Bharti, S.K.; Patel, S.K.; Nath, G., Tilak, R., Singh, S.K; Transition Metal Chemistry., 2010.

8. Kumar, S.; Dhar, D.N.; Saxena, P.N.; Applications of metal complexes of Schiff bases-a review, Journal of Scientific and Industrial Research., 2009, 68(3), 181-187.

9. Nazirkar, Bhushan.; Mandewale, Mustapha.; Yamgar, Ramesh.; Journal of taibah university for science., 2019, 13(1), 440-449.

10. Sreenatha Sharma, T.; Vasavi, G.S.S.; Sreeramulu, J.; Acta Ciencia Indica., 2017, $X L I I I C(3), 407-410$.

11. Olar, R.; Badea, M.; Marinescu, D., Carmen Chifiriuc, M.; Bleotu, C.; Nicoleta Grecu, M.; Iorgulescu, E.E., Lazar, V.; Eur. J. Med. Chem., 2010, 45, 3027.

12. Ravanasiddappa, M.; Sureshg, T.; Syed, K.; Radhavendray, S. C.; Basavaraja, C.; S. D. Angadi, S.D.; E J. chem., 2008, 5(2), 395.

13. Sumathi, R.B.; Halli, M.B.; Bioinorg. Chem. Appl., 2014, 1.

14. Franz, AM.; Roland, CF.; Mark, S.; Andres,
RA.; Diana, HT.; Salah, SM.; Metal(II) complexes of compartmental poly nuclear Schiff bases containing phenolate and alkoxy groups. Crystals., 2016, 6(9), 1-17.

15. Kumar, V.A.; Sarala, Y.; Siddikha, A.; Vanitha, S.; Babu, S.; Reddy, AV.; Synthesis, characterization antimicrobial and antioxidant activities of 2,4-dihydroxybenzaldehyde-4phenyl-3- thiosemicarbazone (DHBPTSC) and its $\mathrm{Pd}(\mathrm{II}), \mathrm{Ni}(\mathrm{II}) \mathrm{dppm}$ mixed ligand and $\mathrm{Cu}$ (II) complex having heterocyclic bases. $J$ Appl Pharm Sci., 2018, 8(04), 07, 1-8.

16. Mishra, A.P.; Mishra, R.K.; Srivastava, S.P.; J.Serb.Chem.Soc., 2009, 74, 523-535.

17. Ranga Reddy, G.N.; Kondaiah, S.; Nagaraja Setty, K.; Mallikarjuna Rao, R.; Sreeramulu, J.; Orient. J. Chem., 2012, 28, 1673-1683.

18. Suraj B. Ade.; Deshpande, M.N.; Kolhatkar, D.G.; Int.J. ChemTech Res., 2012, 4(2), 578-583.

19. Sujamol, M.S.; Athriya, C.J.; Sindhu, Y.; Mohanan, K.; Speectrochim.Acta., 2010, 75A; 106.

20. Basim Hatim Al-Zaidi.; Mohammed Mujbel Hasson.;, Ahmad Hussein Ismail Journal of Applied Pharmaceutical Science., 2019, 9 (04), 045-057.

21. Shigehisa, A.; Tatsuya, N.; Novel thiosalamo ligand as a remarkably stable N2S2 salen-type chelate and synthesis of a nickel(II) complex. Inorg Chem., 2005, 44(5), 1205-07.

22. Bushra Begum, A.; Asha, M.S.; Shaukath Ara Khanum.; Chem Sci Rev Lett, 2014, 3(11), 673-684.

23. Tas, E.; Kilic, A.; Konak, N.; Yilmaz, I.; Polyhedron., 2008, 27, 1024.

24. Bimal Kumar.; Rai, B.K.; Nisha Ambastha.; Orient. J. Chem., 2011, 27, 1173-1178. 